\title{
Application of Formative Assessments to Vocational College English Teaching and Learning
}

\author{
Wenyi LIU \\ Foreign Language Group \\ Dalian Light Industry School \\ Dalian 116024, China \\ 1020241462@qq.com
}

\author{
Shouju LI \\ Department of Engineering Mechanics \\ Dalian University of Technology \\ Dalian 116024, China \\ 229461048@qq.com
}

\begin{abstract}
The formative assessment is more helpful to stimulate the student English learning motivation and enhance student studying ability. In the English teaching and learning process to vocational college students, teachers should use formative assessment and other types of assessment as an elementary to assess the students' English learning. The investigation shows that it is very important to help the students to get back the English learning motivation and give them the desire to learn English well in higher vocational college. During the process of assessing and learning, the students' learning motivation has been stimulated, and they will find their confidences in English learning and to form a good learning habit.
\end{abstract}

Keywords-Formative assessment; English teaching and learning; Learning motivation; Self-learning ability

\section{INTRODUCTION}

Formative assessment provides feedback and evaluation to the teachers and students during studying process in order to adjust teaching and studying contents and measures that are based on collected data and information. Formative assessment can obviously enhance teaching and studying quantity and help student to become high effective autonomous learner. Formative assessment aims directly at ongoing teaching activities, and pays attention to the teaching process rather than teaching results. It is designed for ongoing teaching activities with feedback information, with the purpose of improving the quality of the activities. Therefore, it is a dynamic assessment running through the teaching process constantly. Deng investigated mainly the influence of formative assessment upon learning strategies. So as to testify the effectiveness of formative assessment application in the promotion of students' learning strategy in vocational college, the author has conducted a 20-week study on 76 freshmen in Sichuan College of Architectural Technology [1]. Wiliam reported on the achievement of secondary school students who worked in classrooms where teachers made time to develop formative assessment strategies. A total of 24 teachers were supported over a six-month period in exploring and planning their approach to formative assessment, and then, beginning in September 1999, the teachers put these plans into action with selected classes [2]. Wu pointed out that to promote the college English teaching, students must carry out selfassessment and mutual assessment, teachers must reform their classroom management mode, and the teaching affairs office must build up perfect teaching platform [3]. Zhao introduced an implementation procedure of formative assessment in Shenyang University and analyzed the advantages and significance of formative assessment in college English teaching among the online learning activities, capacities, and evaluation conclusions [4]. Current assessment practices applied to English teaching in senior high schools are summative and dominated by standardized tests, which leads to teaching for testing, not teaching for learning--the ultimate goal of assessment.

The implementation of curriculum reforms promotes the assessment system to develop all-round students and emphasizes the importance of formative evaluation to college students' development. Research about the formative assessment in various subjects continuously increases. The purpose of the study was to investigate the effect of applying formative assessment to English teaching in senior high schools in terms of the improvement of students' English achievements, learner autonomy and self-efficacy.

\section{THEORETICAL FOUNDATIONS AND VALUES OF FORMATIVE ASSESSMENT IN ENGLISH TEACHING AND LEARNING}

Formative assessment is defined as a term based on the concept of Formative evaluation used in evaluating programs and projects. The Formative part of program evaluation attends to the process of a program in order to provide immediate feedback which could lead to improvement.

Formative assessment is the assessment of students' learning process, attitudes, strategic approaches and emotional awareness, so as to confirm the potential of students, find the problems existing in learning of students, promote and develop students' learning strategies. From the needs of assessors as well as assessment object, formative assessment emphasizes not merely the teaching process, but pays more attention to learning process, and insists on multi-assessment to the great importance to teacher-student interaction and cultivating students' language application ability, which helps to form self-learning ability and learning strategies, 
and thus improve teaching quality to meet the requirements of teaching targets.

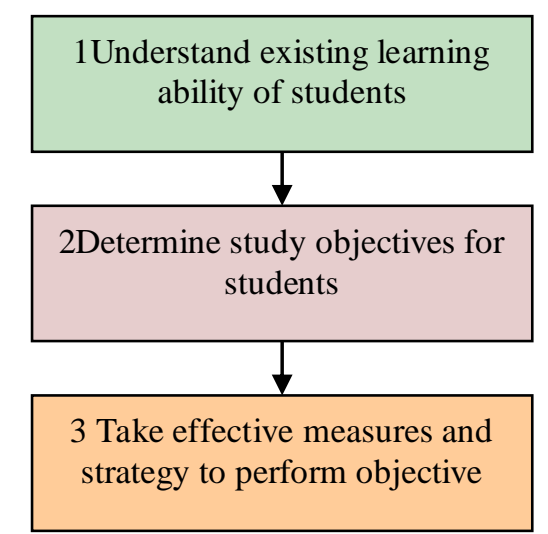

Fig. 1 Main process of English teaching and learning based on formative assessment

Main process of English teaching and learning based on formative assessment is determined as three steps as shown in Fig.1 : 1) Understand study starting point for students, 2) Determine study objectives for students, which is the expected target for students; 3 ) Take effective measures and strategy to perform objective. According to the principles of the application of vocational college English teaching and the research results, it is proposed that formative assessment should be employed to improve the learning ability of vocational college students to solve the problems existing in college English teaching evaluation system.

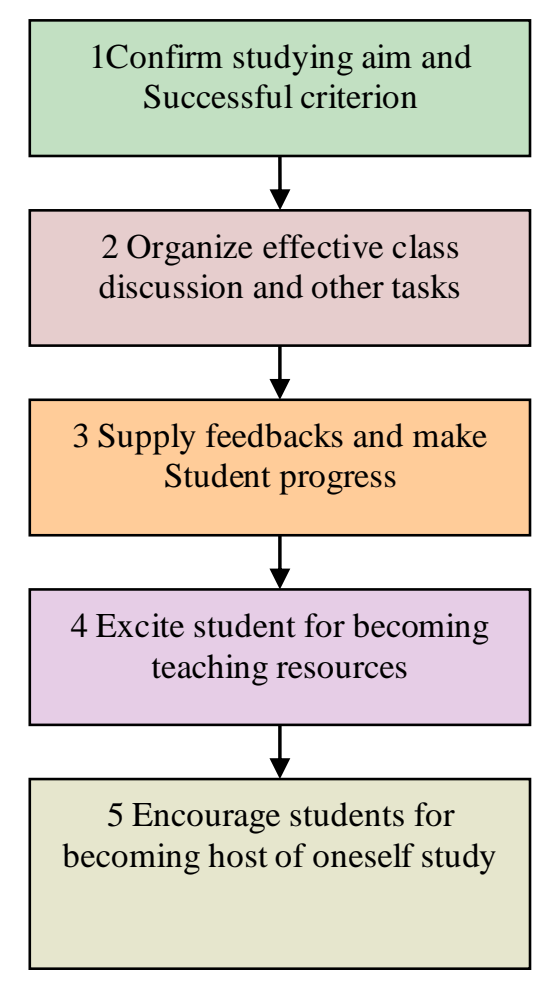

Fig. 2 Main strategies of formative assessment in English teaching and learning

Main strategies of formative assessment in English teaching and learning are shown in Fig. 2. The essence of formative assessment is to set a established target, and then to perform this target by taking some methods. The formation of evaluation information is helpful for students, who must be able to understand feedback and take advantage of it. However, the evaluation must be effective; students must have to learn to evaluate themselves so that they can understand the main goals of learning and how to achieve them. The key elements of effective self-assessment include the clear transparency of the evaluation criteria, the 
development of students' participation in learning goals and evaluation criteria, and the clarity of the system. The evaluation process and recording system help students to evaluate themselves.

The formative assessment affects the students' ability of doubting. Lacking of doubting ability is the main problem of the Chinese students. The students obey what the teacher says, and believe that what the teacher says are absolutely right. But, the process of learning is not only for the students, but also for the teachers, so formative assessment is helpful for the students to form a good habit of learning and it is also can help the students to improve their learning ability, to rebuild their confidence of learning and to be a life long learner.

\section{ApPlication of Formative AsSESSMENTS to Vocational COLLEGE ENGLiSh TeACHING AND LEARNING}

Formative assessment encourages cooperation among students, not competition or comparison. It focuses on student's progress and ability, not weakness and failure. Therefore, it can help students to build up their confidence, and strengthen their ability of sustainable development. Learning effect should be assessed from three dimensions, namely, students' self-judgment, peer response and teachers' evaluation. Students' self-judgment focuses on the interest in learning, attitudes, strategies, participation, cooperation and development status of oral English, and it provides a chance for students to continual process of reflection, improvement and self-improvement in order to finally get a comprehensive and correct assessment. In the process of college English teaching, students must be urged to conduct self-assessment for their listening, speaking, reading, writing, translation and other capabilities.

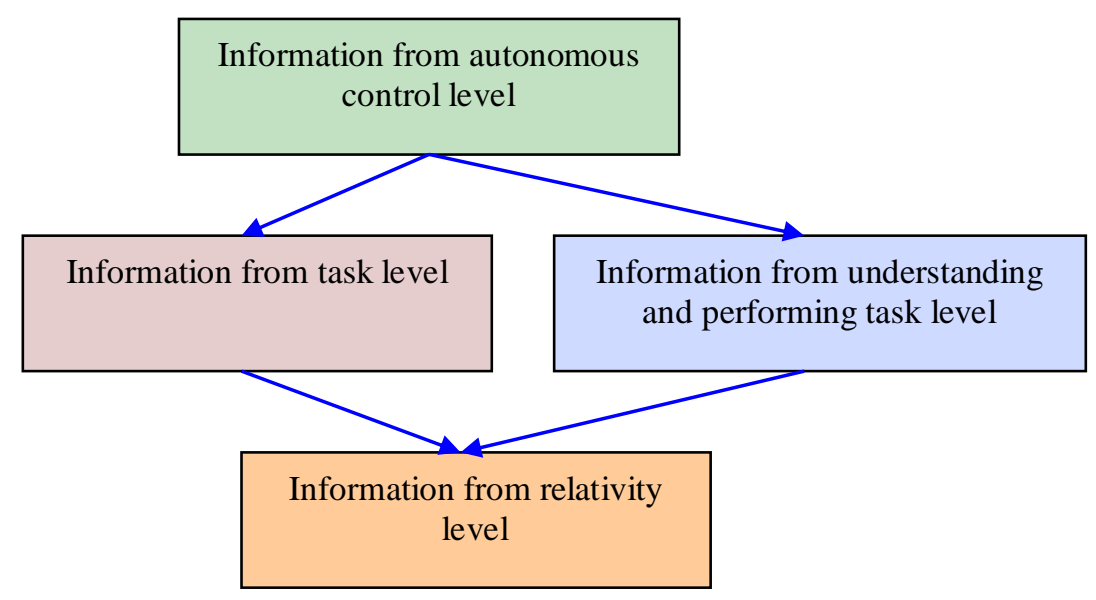

Fig. 3 Collected main information of formative assessment during English teaching and learning

Information feedback is a main part in formative assessment. The complex feedback information is classified as four types, as shown in Fig.3: 1) Information from autonomous control level, which includes self-monitoring, self-directing, and self-adjusting; 2) Information from task level, which includes information induced from task understanding; 3) Information from understanding and performing task level, which is relative to strategy of self error check; 4) Information from relativity level, which pays attention to self-assessment. There is no one form of evaluation that applies to all teachers. All the students and all teachers need to find the right thing to do it. They need to rethink their teaching and evaluation practices, discuss with other teachers, and observe other teachers trails. But there are some common forms and key components of the formative evaluation, which can be the starting point for new attempts.

\section{CONCLUSIONS}

The formative assessment can improve students' learning ability, increase their capability to learn more English knowledge, improve their language skills. The student enthusiasm to English learning can be enhanced accordingly. The formative assessment is a learning process. During this learning process for English teaching, the students can adjust their learning strategy and motivation by evaluating themselves. The students can get more useful feedbacks which can be used to direct their learning methods. The formative assessment can make students to perform great progress.

\section{REFERENCES}

[1] D.Z. Deng, "Formative assessment and English learning strategies-An experiment on teaching vocational college English," Overseas English, vol.12, pp. 103-105, 2012.

[2] D. Wiliam, C. Lee, C. Harrison, "Teachers developing assessment for learning: impact on student achievement, Assessment in Education: Principles, Policy \& Practice," vol. 11(1) pp. 49-67, 2004. 
[3] D.X. Wu and P. L. Mei, "An analysis on promoting formative assessment in college English teaching," International Conference on Social Science and Education, pp. 275-279, 2012.

[4] J. Zhang, "An implementation of formative assessment system in college English teaching," Economic, Business Management and Education Innovation, pp. 370-373. 2013. 